\title{
Breast Segmentation Procedure from Upper Body 3D Scans Using Open Source Software Blender
}

\author{
Michaela HASSMANN*1, Jacqueline DASTL2 , Wolfgang $\mathrm{KRACH}^{2}$ \\ 1 University of Vienna, Vienna, Austria; \\ ${ }^{2} \mathrm{CAE}$ Simulation \& Solutions $\mathrm{GmbH}$, Vienna, Austria \\ DOI: $10.15221 / 18.207 \quad$ http://dx.doi.org/10.15221/18.207
}

\begin{abstract}
The definition of 3D Finite Element (FE) volume models of female torso requires geometry information of naked surface and material properties of human tissues. Analog methods determining breast volume by water immersion of breast or plaster casts are still referred to as gold standard [1]. However, the human body surface is nowadays digitized by 3D scanners, which have become handy and affordable in the last years $[2,3]$. The term segmentation describes the strategy for separating breast tissue region from 3D surface scans of the female thorax. Different segmentation strategies are proposed in literature, either by outline definition $[3,4,5,6]$ or by creating a parametric surface (Coons patch) from boundary curves using fiducial points $[1,4]$. The volume between breast base (artificial chest wall) and skin surface forms breast volume. In this study, 59 participants (19 to 67 years, bra size 75B to 95G) were scanned with a low-cost hand-held $1^{\text {st }}$ generation Sense ${ }^{\mathrm{TM}}$ 3D scanner (3D Systems Inc., Rock Hill, SC, USA) in two different positions: standing upright on a turntable and lying on the back (supine), both with the palms of their hands resting on the anterior superior iliac spine. The supine position increases the visibility of the inframammary fold, a common problem especially in ptotic breasts [7]. The breast outline was marked with skin marker. From the 3D scan data in *.ply file format containing geometric and color information, triangular elements representing breast tissue and other regions were selected in open source software Blender 2.79b [8]. All selected regions were exported separately as *.stl files for further data processing in FE pre-processor Patran 2014.1 (MSC.Software Corporation, Santa Ana, CA, USA), where breast base was created and breast volume was calculated. Breast volume was compared to bra size and sister size groups, respectively, which usually shows relatively low accordance [9], indicating the importance of application and market specific determination of breast shape and volume.
\end{abstract}

Keywords: Finite Element modelling, breast volume, inframammary fold, Sense ${ }^{\mathrm{TM}} 3 \mathrm{D}$ scanner

\section{Introduction}

Female breast shape and volume are required for medical, clothing and biomechanical purposes. In aesthetic surgery, degree of ptosis, breast deformity or symmetry of surgery outcome are judged $[2,7]$. In clothing industry, the aim is either mass customization for upper body (every day and sports) underwear and clothing according to sizing standards, or for made-to-measure (personal customization) [10] e.g. in post-surgery compression bras [11]. European Standard DIN EN 13402-3:2017-12 [12] requires only underbust and bust circumference for bra size designation. In addition, it states that circumference and cup measurements may vary to balance variations between national markets and manufacturers. This suggests that neither the cup size according to the standard nor the size that fits are reliable measures for breast size. Therefore, breast volume is evaluated for size classification of breast in addition to or rather than bra cup or bra size [9].

The gold standard procedure for the determination of female breast volume is the water displacement measurement by immerging either the breast or plaster casts into water [1]. However, the measurement accuracy of this method is affected by the accuracy of reading. Moreover, variation in participant positioning leads to poor reproducibility [9]. Broad and small breasts do not hang away from the chest wall as much as ptotic breasts, wherefore their volume tends to be underestimated [9]. Furthermore, for bra cup design purposes, a breast volume measurement method that simultaneously measures breast shape, such as scanning technology, is recommended [9]. Female breast volume is nowadays determined mostly from 3D surface scans due to the versatility and handiness of current 3D scanning technology $[2,3]$. The principle of this technology is optical triangulation using either infrared light or class 1 laser [13] acquiring a cloud of surface points (nodes) which form a virtual triangulated surface mesh (elements).

\footnotetext{
*michaela.hassmann@univie.ac.at; +43- 1- 4277- 48883; http://zsu-schmelz.univie.ac.at/en/
} 
The calculation of breast volume requires a distinction of the breast, that covers the area between the mid-axillary line and the sternum, from the female torso, which is called segmentation. In general, automated segmentation of human body scans makes use of geometric algorithms dividing the body into parts according to generic average shapes [14]. This method is applicable for the separation of torso, head and extremities. For the female breast, segmentation is far more sophisticated due to its complex and highly individual shape $[9,15]$ and due to the ambiguity of the outline of the breast [15]. Proposed segmentation strategies in literature use different line and dot patterns (fiducial points) $[3,4,5,6]$. Liu et al. [10] created a method to define breast root shape locating twelve control points every $30^{\circ}$ around the breast. Emphasizing the breast outline on the skin by posing the hand on the waistline or pushing the breast tissue upwards or inwards [15] changes the shape of breast tissue and is therefore not applicable if the breast shape should also be investigated. For the definition of a volume, the triangulated mesh of the chosen surface region must be closed either automatically or manually. The breast base is mostly created as a parametric surface (Coons patch) from boundary curves using fiducial points [1,4]. This breast base represents an artificial chest wall, the posterior boundary to the breast segment, controlled by edge lines delimiting the breast segment [1] to mimic the shape of the anterior chest curvature [7].

While segmentation from 3D surface scans only relies on the outer shape (surface geometry) of the female torso, medical imaging (CT, MRI) allows for more exact segmentation and further separation of human tissues by distinguishing them regarding the density of each material [5]. These methods, however, are expensive and time consuming. Furthermore, the distinction between glandular and fat tissue can be neglected by assigning average mechanical properties of these tissues [5]. Accordingly, medical imaging can be omitted for breast shape and volume determination.

In the recently finished research project "Sports bra optimization by Finite Element simulation of interaction between textile and female breast tissue (FEM-Sports-Bra)", the optimal breast segmentation procedure for determination of breast shape and volume from 3D surface scans had to be defined.

\section{Methods}

\subsection{Participants}

59 women P1 to P59 (19 to 67 years, bra size 75B to 95G), not currently pregnant nor breast feeding and without history of breast surgery, participated in this study. Bra size is given as the size that actually fits meeting bra fitting criteria [9], as the determination according to DIN EN 13402-3:2017-12 underestimates worn size by 1 to 2 cups and it is therefore not representative. All participants signed informed consent, and the study was approved by the ethics committee of University of Vienna.

\subsection{Scanning procedure}

The participants were scanned with a low-cost hand-held $1^{\text {st }}$ generation Sense ${ }^{\mathrm{TM}} 3 \mathrm{D}$ scanner (3D Systems Inc., Rock Hill, SC, USA) in two different positions: standing upright on a turntable and lying on the back (supine), both with the palms of their hands resting on the anterior superior iliac spine. The full scanning procedure is described in [16]. The supine position increases the visibility of the inframammary fold (IMF), a common problem especially in ptotic breasts [7]. Fiducial points and breast outline were marked on the participant with skin marker by the same researcher for all participants (see figure 1). Breast outline marks the area which is recognized as breast tissue that should be inside the bra cup. The upper breast outline was marked according to the visible change of curvature, eventually emphasized by briefly tensing pectoral muscle. The lower outline along the IMF was marked in supine position for ptotic breasts.

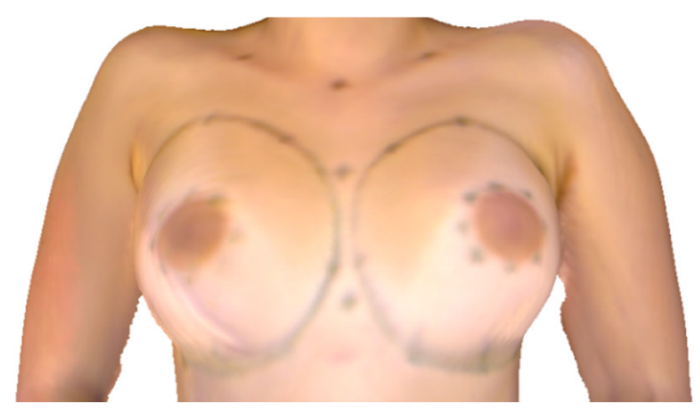

Fig. 1. Fiducial points and lines marked on the female torso (P1, supine position). 


\subsection{Breast segmentation procedure}

The *.ply files of upright and supine position were loaded in software Blender [8]. After deletion of loose vertices and closing of gaps, the mesh was improved by smoothing in Sculpt Mode. Neck, arms and torso below the waist were cut using Knife. In order to reduce amount of data, mesh density was decimated by a ratio of 0.1 (see figure 2 ).
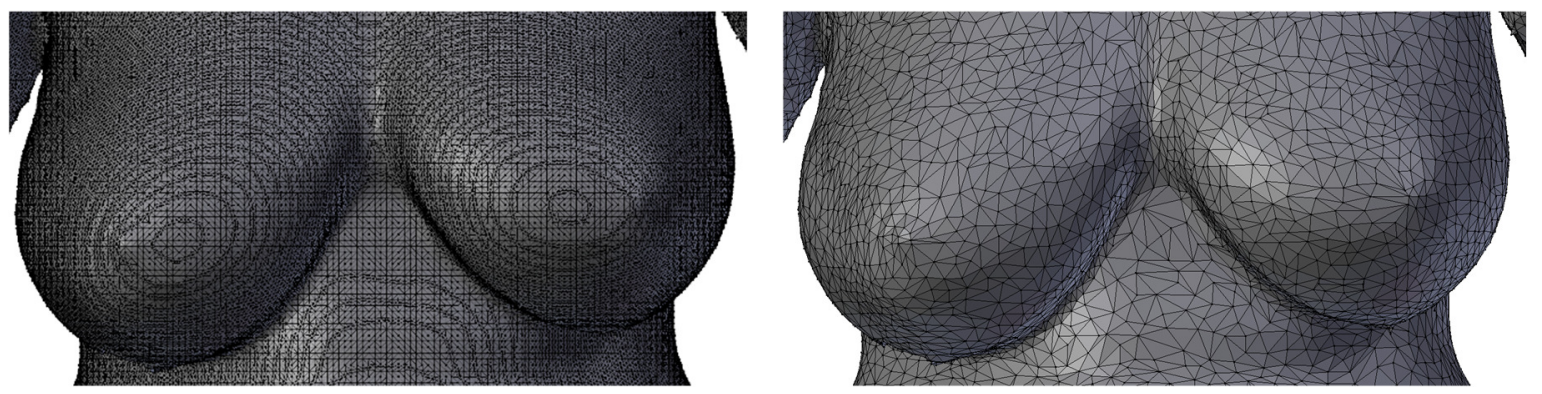

Fig. 2. Close-up view of mesh at breast region before (left) and after decimation (right) (P19).

From the 3D scan in upright position, faces that belong to the breast region were selected according to the marked outline (see figure 3, left) and saved to a separate patch. In addition, breast muscle and lateral fat regions were segmented. When selecting breast volume, literature $[3,4,15]$ often includes the area above the actual breast tissue which is normally not inside the bra cup. In this paper, this area is referred to as muscle due to the fact that this soft tissue overlays the pectoral muscle. Some participants, especially those with larger cup size and higher body mass index, showed a portion of tissue on the lateral side of the breast, which was rather adipose or connective tissue than breast tissue or muscle. This region was not recognized as breast tissue when marking the breast outline, but it is also covered by the bra and therefore it contributes to actual breast volume which should be inside the bra cup (see figure 3, right).
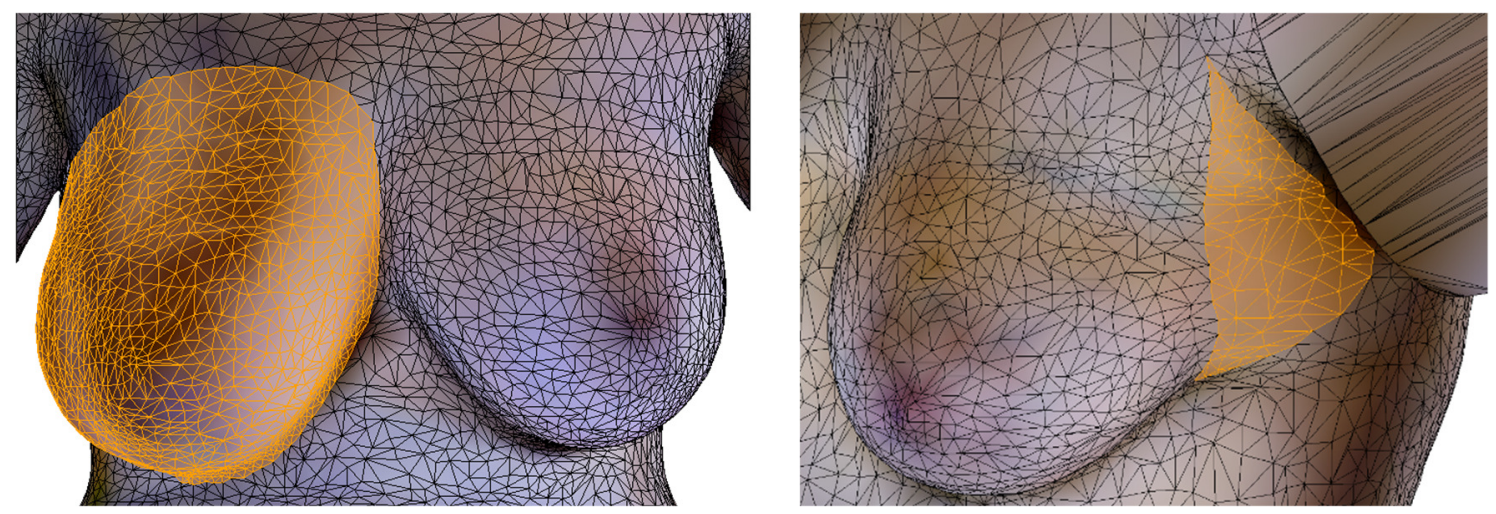

Fig. 3. Left: Segmentation of right breast from 3D scan (P19). Right: Segmentation of lateral fat tissue (P12).

After repeating the selection procedure for all relevant regions from the scan in upright position and segementation of breast tissue from the scan in supine position, the following patches were exported separately as *.stl files (see figure 4):

- body

- breast_right

- breast_left

- muscle_right

- muscle_left

- (lateral_fat_right)

- (lateral_fat_left)

- supine_breast_right

- supine_breast_left 


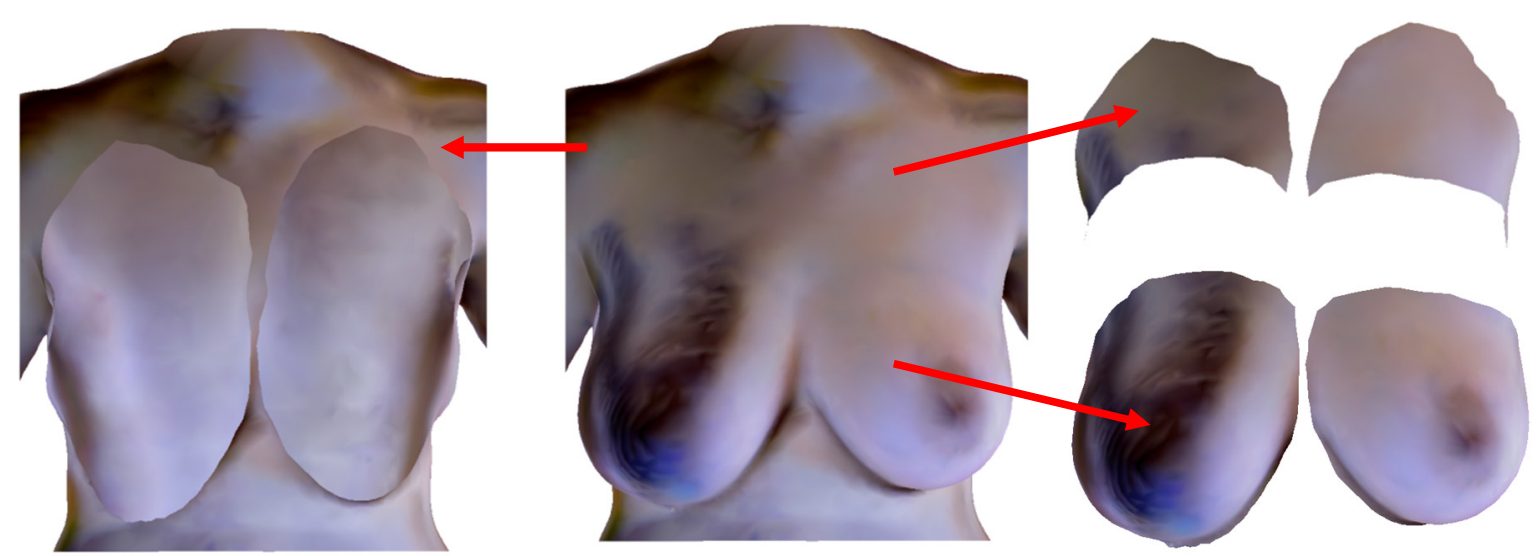

Fig. 4. Segmentation of body, breast and muscle regions from 3D scan in upright position (P19).

These *.stl files were imported separately in the Finite Element (FE) pre-processor Patran 2014.1 for further processing. For the breast base, the gaps in the body patch were closed by filling them with triangular elements. Attempts using a scalable 3D model of a human thorax to mimic the shape of the anterior chest curvature had to be rejected due to the highly individual shape of human body. The inframammary fold (IMF) was defined as the lower outline of the segmented patches supine_breast_right and supine_breast_left (see figure 5, left).
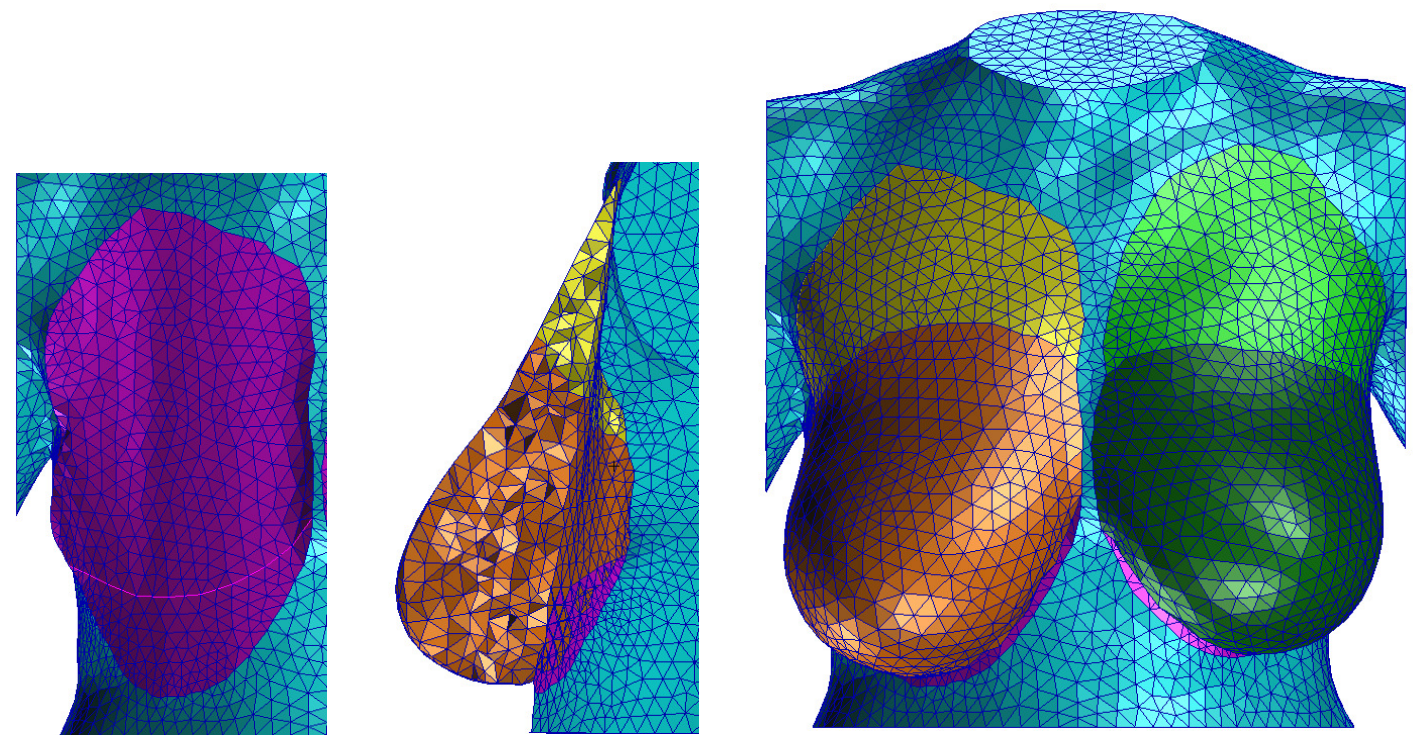

Fig. 5. Left: Breast base including inframammary fold. Middle: Separated breast and muscle volume. Right: Finite Element Model with separated volume regions (P19).

The lower breast area close to the IMF, which was not detected by the 3D scan in upright position, had to be corrected in order to separate breast tissue and body. The closed volume between breast, (lateral_fat), muscle and breast base was filled with tetrahedral elements, which were separated into breast, (lateral_fat) and muscle volumes (see figure 5, middle) to calculate volume automatically by Mass Properties and assigning the respective material properties. The final FE model consisted of a relatively rigid body and flexible breast, (lateral_fat) and muscle regions (see figure 5, right).

\section{Results and Discussion}

\subsection{Breast volume}

The right and left breast volumes obtained by the presented procedure for all participants (except for P2 and P59 due to data problems) was in the range of 128.9 to $1860.0 \mathrm{ml}(691.8 \pm 349.6 \mathrm{ml})$ (see table 1). The breast volume difference for each participant was calculated based on left breast volume, i.e. a positive value indicates higher left breast volume. The relative difference of breast volume was calculated as an absolute value with regard to the left breast volume to make the differences comparable between participants of different bra size. 
Table 1. Breast volume for all participants $(N=57)$.

\begin{tabular}{|c|c|c|c|c|c|c|c|c|}
\hline \multirow{2}{*}{$\begin{array}{l}\text { Bra } \\
\text { size }\end{array}$} & \multirow{2}{*}{ P\# } & \multirow{2}{*}{ BMI } & \multicolumn{2}{|c|}{ Breast volume [ml] } & \multirow{2}{*}{$A M \pm S D$} & \multicolumn{2}{|c|}{ Difference } & \multirow{2}{*}{$A M \pm S D$} \\
\hline & & & Right & Left & & Le-ri [ml] & Rel [\%] & \\
\hline \multirow{5}{*}{$75 B$} & P8 & 21.1 & 216.6 & 232.5 & \multirow{5}{*}{$307.1 \pm 64.8$} & 15.9 & 6.8 & \multirow{5}{*}{$8.2 \pm 1.8$} \\
\hline & P9 & 20.6 & 261.5 & 286.3 & & 24.8 & 8.7 & \\
\hline & P16 & 19.0 & 374.3 & 340.9 & & -33.4 & 9.8 & \\
\hline & P31 & 22.1 & 411.8 & 390.5 & & -21.3 & 5.5 & \\
\hline & P36 & 20.1 & 263.5 & 293.4 & & 29.9 & 10.2 & \\
\hline \multirow{6}{*}{$75 \mathrm{C}$} & P22 & 21.2 & 752.9 & 681.0 & \multirow{6}{*}{$465.5 \pm 119.7$} & -71.9 & 10.6 & \multirow{6}{*}{$10.1 \pm 5.1$} \\
\hline & P24 & 19.8 & 479.1 & 417.6 & & -61.5 & 14.7 & \\
\hline & P26 & 19.5 & 399.6 & 402.9 & & 3.3 & 0.8 & \\
\hline & P27 & 24.8 & 410.0 & 370.0 & & -40.0 & 10.8 & \\
\hline & P30 & 22.3 & 445.9 & 481.4 & & 35.5 & 7.4 & \\
\hline & $\mathrm{P} 40$ & 19.4 & 339.7 & 405.9 & & 66.2 & 16.3 & \\
\hline \multirow{3}{*}{$75 \mathrm{D}$} & P23 & 26.3 & 604.8 & 591.5 & \multirow{3}{*}{$494.9 \pm 76.6$} & -13.3 & 2.2 & \\
\hline & P25 & 25.0 & 450.3 & 409.0 & & -41.3 & 10.1 & $8.0 \pm 4.1$ \\
\hline & P33 & 21.9 & 429.1 & 484.9 & & 55.8 & 11.5 & \\
\hline & P17 & 24.1 & 815.6 & 876.3 & & 60.7 & 6.9 & \\
\hline $75 \mathrm{E}$ & P51 & 20.1 & 588.0 & 675.3 & $725.3 \pm 98.7$ & 87.3 & 12.9 & $10.9 \pm 2.8$ \\
\hline & P53 & 20.8 & 649.9 & 746.7 & & 96.8 & 13.0 & \\
\hline & P19 & 22.4 & 1302.0 & 1028.0 & & -274.0 & 26.7 & \\
\hline $75 \mathrm{~F}$ & P47 & 17.9 & 1012.0 & 980.4 & $1080.6 \pm 129.0$ & -31.6 & 3.2 & $14.9 \pm 11.1$ \\
\hline & P5 & 19.8 & 347.2 & 333.1 & & -14.1 & 4.2 & \\
\hline & P6 & 20.9 & 128.9 & 132.6 & & 3.7 & 2.8 & \\
\hline & $\mathrm{P} 13$ & 21.8 & 482.1 & 550.7 & & 68.6 & 12.5 & \\
\hline $80 \mathrm{~B}$ & P14 & 22.0 & 435.8 & 443.9 & $327.4 \pm 127.1$ & 8.1 & 1.8 & $6.7 \pm 3.6$ \\
\hline & $\mathrm{P} 15$ & 22.6 & 255.8 & 280.9 & & 25.1 & 8.9 & \\
\hline & P29 & 22.0 & 209.0 & 191.9 & & -17.1 & 8.9 & \\
\hline & P35 & 21.8 & 409.9 & 381.2 & & -28.7 & 7.5 & \\
\hline & P3 & 22.1 & 394.4 & 380.1 & & -14.3 & 3.8 & \\
\hline & $\mathrm{P} 11$ & 23.2 & 483.1 & 474.9 & & -8.2 & 1.7 & \\
\hline $80 C$ & $\mathrm{P} 12$ & 25.9 & 446.7 & 450.6 & $508.3 \pm 92.4$ & 3.9 & 0.9 & $1.9 \pm 1.3$ \\
\hline & P43 & 20.1 & 594.5 & 577.9 & & -16.6 & 2.9 & \\
\hline & P49 & 24.8 & 640.8 & 640.0 & & -0.8 & 0.1 & \\
\hline D80 & P1 & 22.8 & 697.1 & 726.1 & & 29.0 & 4.0 & \\
\hline 800 & P28 & 22.7 & 713.8 & 650.1 & $696.8 \pm 28.8$ & -63.7 & 9.8 & $0.9 \pm 2.9$ \\
\hline & P41 & 24.9 & 1054.0 & 840.2 & & -213.8 & 25.4 & \\
\hline $80 \mathrm{E}$ & P45 & 24.9 & 1005.0 & 922.2 & $982.6 \pm 77.2$ & -82.8 & 9.0 & $12.3 \pm 9.7$ \\
\hline & P50 & 25.8 & 1049.0 & 1025.0 & & -24.0 & 2.3 & \\
\hline $80 \mathrm{~F}$ & P18 & 21.3 & 900.0 & 1041.0 & $970.5 \pm 70.5$ & 141.0 & 13.5 & \\
\hline $80 G$ & P58 & 23.0 & 1009.0 & 1070.0 & $1039.5 \pm 30.5$ & 61.0 & 5.7 & \\
\hline & P38 & 26.2 & 490.8 & 546.9 & & 56.1 & 10.3 & \\
\hline $85 B$ & P44 & 25.1 & 401.8 & 402.2 & $464.2 \pm 52.5$ & 0.4 & 0.1 & $6.6 \pm 4.6$ \\
\hline & P57 & 29.4 & 447.9 & 495.4 & & 47.5 & 9.6 & \\
\hline & $\mathrm{P} 10$ & 23.0 & 976.5 & 925.5 & & -51.0 & 5.5 & \\
\hline & P21 & 26.1 & 647.2 & 733.3 & & 86.1 & 11.7 & \\
\hline $85 \mathrm{D}$ & P39 & 28.8 & 794.2 & 775.3 & $845.4 \pm 101.2$ & -18.9 & 2.4 & $5.4 \pm 3.8$ \\
\hline & $\mathrm{P} 42$ & 26.4 & 861.3 & 867.9 & & 6.6 & 0.8 & \\
\hline & P48 & 25.6 & 903.9 & 969.3 & & 65.4 & 6.7 & \\
\hline & $\mathrm{P} 7$ & 28.7 & 883.1 & 948.1 & & 65.0 & 6.9 & \\
\hline 85E & $\mathrm{P} 46$ & 28.3 & 1013.0 & 1176.0 & $1005.1 \pm 108.9$ & 163.0 & 13.9 & $10.4 \pm 3.5$ \\
\hline 90D & P37 & 28.3 & 723.0 & 821.0 & $772.0 \pm 49.0$ & 98.0 & 11.9 & \\
\hline & P32 & 29.3 & 1282.3 & 1428.3 & & 146.0 & 10.2 & \\
\hline 90E & P52 & 31.3 & 1315.2 & 1134.0 & $1290.0 \pm 105.1$ & -181.1 & 16.0 & $13.1 \pm 2.9$ \\
\hline & P20 & 26.1 & 729.1 & 830.3 & & 101.2 & 12.2 & \\
\hline 950 & P55 & 35.9 & 946.3 & 889.8 & $848.9 \pm 80.4$ & -56.5 & 6.3 & $9.3 \pm 2.9$ \\
\hline 95D & P54 & 35.3 & 910.2 & 933.5 & $921.9 \pm 11.7$ & 23.3 & 2.5 & \\
\hline & $\mathrm{P} 4$ & 33.5 & 1351.0 & 1134.0 & & -217.0 & 19.1 & \\
\hline 95E & P34 & 35.9 & 1422.0 & 1389.0 & $1324.0 \pm 112.5$ & -33.0 & 2.4 & $10.8 \pm 8.4$ \\
\hline $95 \mathrm{G}$ & P56 & 27.8 & 1838.6 & 1860.0 & $1849.3 \pm 10.7$ & 21.4 & 1.1 & \\
\hline
\end{tabular}


In figure 6 , the breast volume is shown as $\mathrm{AM} \pm \mathrm{SD}$ for each bra size separately.

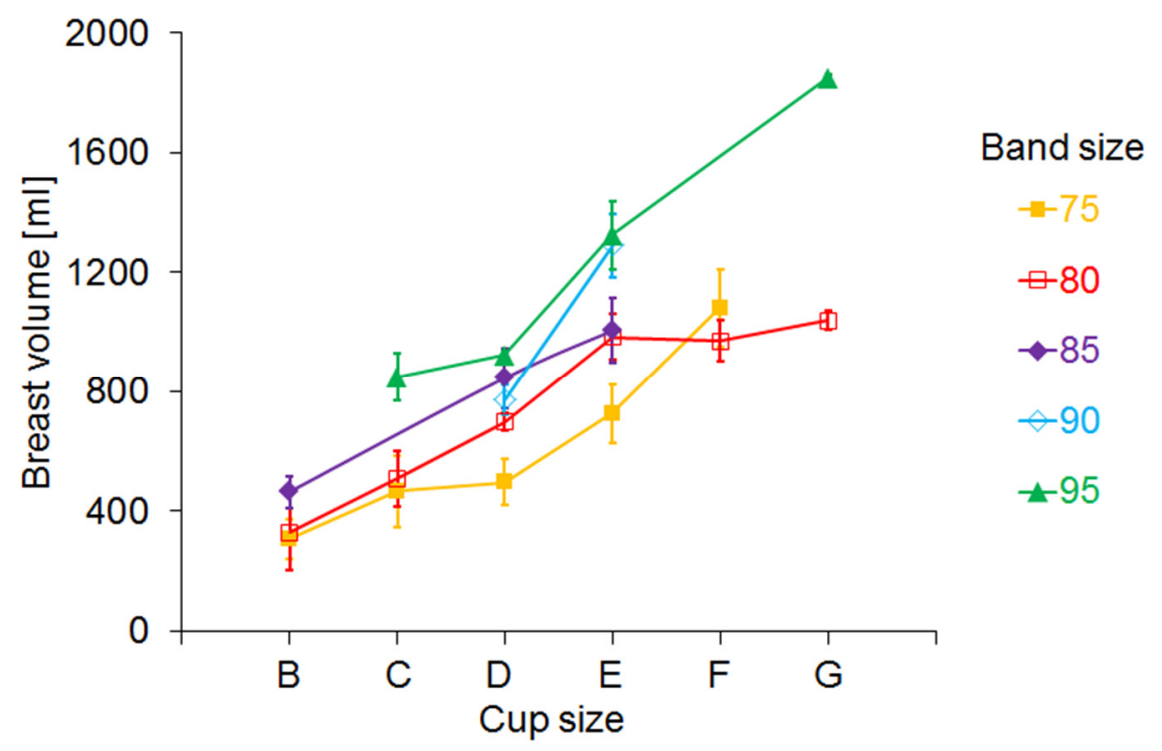

Fig. 6. Breast volume $(A M \pm S D)$ according to band and cup size.

The proposed system of sister sizes [17], which are referred to as having equal breast volume, are depicted in figure 7 (left) (e.g. group $1=75 \mathrm{~B}$; group $2=75 \mathrm{C}, 80 \mathrm{~B} ; \ldots$ ). For all bra sizes for which data is available, the mean breast volume arranged by sister size groups is shown in figure 7 (right).

\begin{tabular}{l|c|c|c|c|c|}
6 & \multicolumn{2}{c}{7} & \multicolumn{2}{c}{9} & \multicolumn{1}{c}{10} \\
\cline { 2 - 6 } 5 & $75 \mathrm{G}$ & $80 \mathrm{G}$ & $85 \mathrm{G}$ & $90 \mathrm{G}$ & $95 \mathrm{G}$ \\
\cline { 2 - 6 } & $75 \mathrm{~F}$ & $80 \mathrm{~F}$ & $85 \mathrm{~F}$ & $90 \mathrm{~F}$ & $95 \mathrm{~F}$ \\
\cline { 2 - 6 } 3 & $75 \mathrm{E}$ & $80 \mathrm{E}$ & $85 \mathrm{E}$ & $90 \mathrm{E}$ & $95 \mathrm{E}$ \\
\cline { 2 - 6 } 2 & $75 \mathrm{D}$ & $80 \mathrm{D}$ & $85 \mathrm{D}$ & $90 \mathrm{D}$ & $95 \mathrm{D}$ \\
\cline { 2 - 6 } 1 & $75 \mathrm{C}$ & $80 \mathrm{C}$ & $85 \mathrm{C}$ & $90 \mathrm{C}$ & $95 \mathrm{C}$ \\
\cline { 2 - 6 } & $75 \mathrm{~B}$ & $80 \mathrm{~B}$ & $85 \mathrm{~B}$ & $90 \mathrm{~B}$ & $95 \mathrm{~B}$ \\
\cline { 2 - 5 } & & & & &
\end{tabular}

\begin{tabular}{|c|c|c|c|c|}
\hline & 1039,5 & & & 1849,3 \\
\hline 1080,6 & 970,5 & & & \\
\hline 725,3 & 982,6 & 1005,1 & 1290,0 & 1324,0 \\
\hline 494,9 & 696,8 & 845,4 & 772,0 & 921,9 \\
\hline 465,5 & 508,3 & & & 848,9 \\
\hline 307,1 & 327,4 & 464,2 & & \\
\hline
\end{tabular}

Fig. 7. Left: Sister size groups. Right: Breast volume (AM) according to bra size.

Plotting arithmetic mean of breast volume over sister size groups shows that breast volume generally increases with group. Considering the standard deviation of each group, ranges overlap between most of the groups (see figure 8).

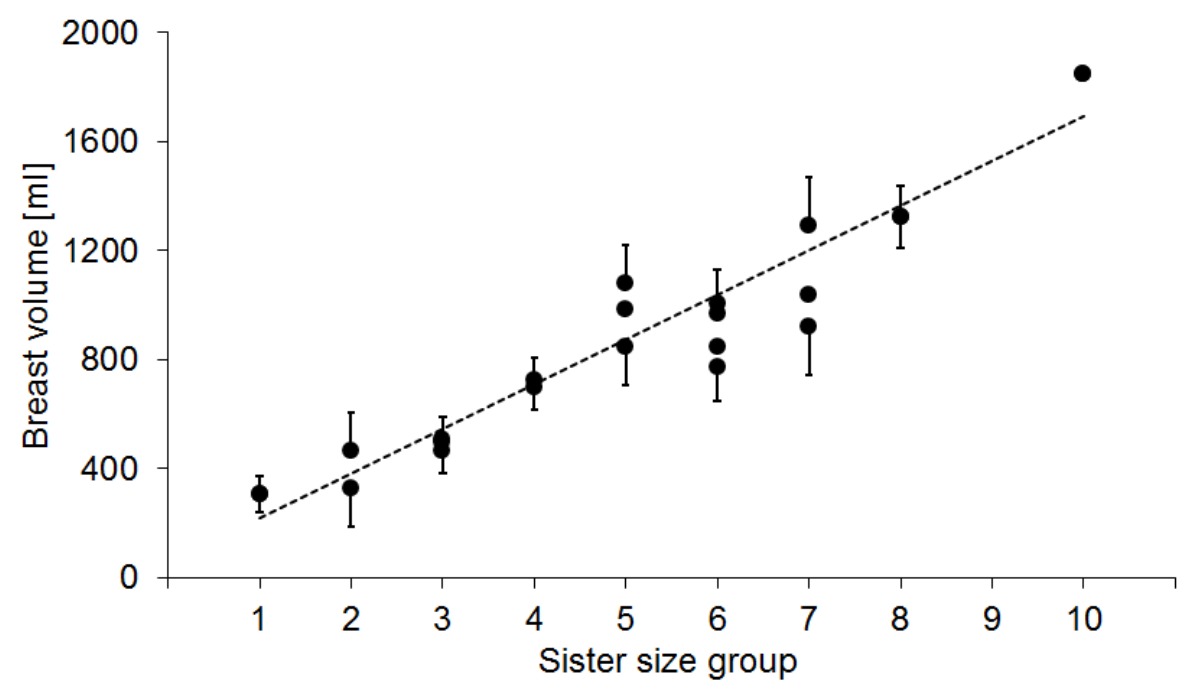

Fig. 8. Breast volume $(A M \pm S D)$ according to sister size groups. 
The absolute difference between right and left breast volume was between 0.4 and $274.0 \mathrm{ml}$ or 1.1 and $14.9 \%$ relative to the left breast volume of the participant averaged for each bra size separately (see figure 9).

\begin{tabular}{|c|c|c|c|c|}
\hline & 5.7 & & & 1.1 \\
\hline 14.9 & 13.5 & & & \\
\hline 10.9 & 12.3 & 10.4 & 13.1 & 10.8 \\
\hline 8.0 & 6.9 & 5.4 & 11.9 & 2.5 \\
\hline 10.1 & 1.9 & & & 9.3 \\
\hline 8.2 & 6.7 & 6.6 & & \\
\hline
\end{tabular}

Fig. 9. Breast volume difference (AM in \%) according to bra size.

Figure 10 shows the positive correlation between absolute breast volume difference and body mass index (BMI). One-tailed Pearson's coefficient of correlation $R=0.231$ is significant $(p=0.042)$.

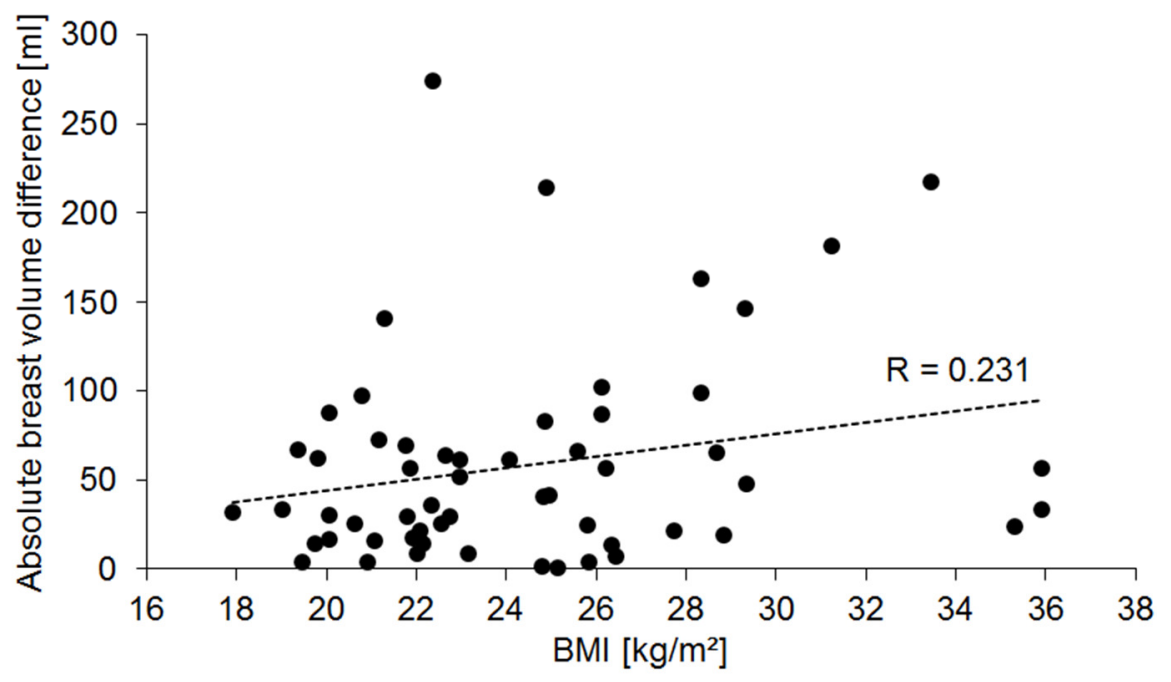

Fig. 10. Correlation between absolute breast volume difference and BMI.

\section{Conclusions}

The reliable determination of breast shape and volume is crucial in several fields. Using 3D surface scans of the female torso for this purpose requires the separation of breast tissue region. For this separation the term segmentation is used, mostly for CT or MRI images, but in this paper a similar strategy was followed using 3D surface scans. In addition to the breast tissue region, the regions above and lateral to the breast were segmented taking into account that they are composed of muscle or adipose tissue. Similar to the female breast, these elastic tissues form a volume which moves relative to the rather rigid torso.

Different breast segmentation strategies are proposed in literature [2,4,5,6], mostly using markups. The upper and lateral breast outline was marked on the skin as was evident by a visible change of curvature at the transition of breast and breast muscle or lateral adipose tissue. For the lower outline representing inframammary fold (IMF), the breast was slightly lifted for pert breasts or it was marked in supine position for ptotic breasts to avoid blurred lines. For the breast base, attempts were made using a scalable 3D model of a human thorax to mimic the shape of the anterior chest curvature. Due to the highly individual shape of human body, this procedure had to be rejected. The gaps in the body patch were closed manually and the IMF was projected onto the breast base in Finite Element pre-processor Patran 2014.1 before creating the FE model for each participant. Further steps are undertaken to automate segmentation and breast volume calculation by Python scripting in Blender.

The right and left breast volumes obtained by this segmentation procedure for 57 participants (bra size $75 \mathrm{~B}$ to $95 \mathrm{G}$ ) were similar to those in other studies [9], in which breast volume was measured by water immersion and bra size was given in Australian sizes (e.g. Australian band size 12 corresponds to EU band size 75). The standard deviation within each bra size is relatively high compared to the mean 
value, especially for smaller bra sizes e.g. 80B which exhibited a range of breast volume from 129 to $551 \mathrm{ml}$. Assuming that bra manufacturers adhere to sister sizing [17], the mean breast volume for all bra sizes within one sister size group should be approximately the same. The large ranges of breast volumes within groups and overlapping ranges between groups support that sister sizing tends to confuse rather than inform, as the breast volumes are not congruent for sister sizes [18].

Breast asymmetry was found in up to $82 \%$ of women $[19,20]$ measuring different distances. In a study with 125 participants, the majority had a certain amount of difference between right and left breast volume: 0 to $10 \mathrm{ml}(2.2 \%), 11$ to $25 \mathrm{ml}(21.9 \%), 26$ to $50 \mathrm{ml}(28.9 \%), 51$ to $100 \mathrm{ml}(29.3 \%)$, larger than $101 \mathrm{ml}(17.7 \%)$ [20]. In this study, comparable absolute differences could be found, with the majority of participants between 51 and $100 \mathrm{ml}(31.6 \%)$. The absolute difference does not show any clear trend, neither for bra cup nor sister size group, whereas larger absolute differences are tendentially more frequent in larger bra sizes. The information on bra size or breast volume was not given in [20], but in [19] the difference between right and left breast volume increased with cup size and chest-wall circumference (band size). Studies stating the left breast to be larger [19] can be supported, as the left breast volume was larger for 31 out of 57 participants. The dominant side as a criterion for breast asymmetry [21] was not asked in this study. The significantly positive correlation between breast volume difference and body mass index (BMI) as in [19] can be confirmed, but with a rather low coefficient of correlation.

\section{Acknowledgments}

This work is part of the research project "Sports bra optimization by Finite Element simulation of interaction between textile and female breast tissue (FEM-Sports-Bra)" (January 2016 to February 2018), funded by Vienna Business Agency.

\section{References}

[1] H. Henseler et al., "Investigation into accuracy and reproducibility of a 3D breast imaging system using multiple stereo cameras", in Journal of Plastic, Reconstructive \& Aesthetic Surgery, 64, 2011, pp.577-582, http://dx.doi.org/10.1016/j.bjps.2010.08.044.

[2] K. C. Koban, T. L. Schenck and R. E. Giunta, "Using Mobile 3D Scanning Systems for Objective Evaluation of Form, Volume, and Symmetry in Plastic Surgery: Intraoperative Scanning and Lymphedema Assessment", in Proc. of $7^{\text {th }}$ Int. Conf. on 3D Body Scanning Technologies, Lugano, Switzerland, 2016, pp.130-131, http://dx.doi.org/10.15221/16.130.

[3] S. B. Choppin, H. Probst, A. Goyal, S. Clarkson and J. Wheat, "Breast Volume Calculation Using a Low-Cost Scanning System", in Proc. of $4^{\text {th }}$ Int. Conf. on 3D Body Scanning Technologies, Long Beach, USA, 2013, pp.12-20, http://dx.doi.org/10.15221/13.012.

[4] G. P. Reece et al., "3D surface imaging of the human female torso in upright to supine positions", in Medical Engineering \& Physics, Vol.37, No.4, 2015, pp.375-383, http://dx.doi.org/10.1016/j.medengphy.2015.01.011.

[5] A. Pérez del Palomar, B. Calvo, J. Herrero, J. López and M. Doblaré. "A finite element model to accurately predict real deformations of the breast", in Medical Engineering \& Physics, Vol. 30 ,

No.9, 2008, pp.1089-1097, https://dx.doi.org/10.1016/j.medengphy.2008.01.005.

[6] H. Khatam, G. P. Reece, M. C. Fingeret, M. K. Markey and K. Ravi-Chandar, "In-vivo quantification of human breast deformation associated with the position change from supine to upright", in Medical Engineering \& Physics, Vol. 37, No.1, 2015, pp.13-22, https://dx.doi.org/10.1016/j.medengphy.2014.09.016.

[7] C. E. Coltman, D. E. McGhee and J. R. Steele, "Three-dimensional scanning in women with large, ptotic breasts: implications for bra cup sizing and design", in Ergonomics, Vol.60, No.3, 2017, pp.439-445, https://dx.doi.org/10.1080/00140139.2016.1176258.

[8] Open Source 3D creation. Free to use for any purpose, forever, https://www.blender.org/,accessed 2018.

[9] D. E. McGhee and J. R. Steele, "Breast volume and bra size", in International Journal of Clothing Science and Technology, Vol.23, No.5, 2011, pp.351-360, https://dx.doi.org/10.1108/09556221111166284.

[10] Y. Liu, C. L. Istook, K. Liu and J. Wang, "Innovative method for creating fitted brassiere wire prototype based on transformation matrix algorithm", in The Journal of the Textile Institute, Vol.7, 2017, pp.1-6, http://dx.doi.org/10.1080/00405000.2017.1326366. 
[11] S. Gho, B. J. Munro, S. C. Jones and J. R. Steele, "Evidence-based recommendations for building better bras for women treated for breast cancer", in Ergonomics, Vol.57, No.5, 2014, pp.774-786, https://dx.doi.org/10.1080/00140139.2014.897377.

[12] DIN EN 13402-3:2017-12, Size designation of clothes - Part 3: Size labelling based on body measurements and intervals.

[13] Sense ${ }^{\mathrm{TM}} 2$ 3D scanner. Capture your world in 3D. User Guide. Original instructions, http://cubify.s3.amazonaws.com/Scanners/Sense/sense 2nd gen user guide win.pdf, accessed 2018.

[14] X. Ju, N. Werghi and J. P. Siebert, "Automatic segmentation of 3D human body scans", in Proc. of IASTED Int. Conf. on Computer Graphics and Imaging, Las Vegas, USA, 2000, pp.1-6.

[15] H.-Y. Lee, K. Hong and E. A. Kim, "Measurement protocol of women's nude breasts using a 3D scanning technique", in Applied Ergonomics, Vol.35, 2004, pp.353-359, https://dx.doi.org/10.1016/j.apergo.2004.03.004.

[16] M. Hassmann, S. Stöger, J. Dastl and W. Krach, "Scanning procedure of female torso using low-cost hand-held SenseTM 3D scanner", in Proc. of $9^{\text {th }}$ Int. Conf. on 3D Body Scanning Technologies, Lugano, Switzerland, 2018.

[17] E. Scott, The Bra Fitting Bible. Calculating and Understanding Bra Size, Morrisville NC, USA, Lulu, 2013.

[18] A. Peterson and M. Suh, "Effect of Bra Style and Size on its Fit and Comfort", in 2016 ITAA Annual Conference Proceedings, Vancouver, Canada, 2016.

[19] A. Losken, I. Fishman, D. D. Denson, H. R. Moyer and G. W. Carlson, "An Objective Evaluation of Breast Symmetry and Shape Differences Using 3-Dimensional Images", in Annals of Plastic Surgery, Vol.55, No.6, pp.571-575, 2005, https://dx.doi.org/10.1097/01.sap.0000185459.49434.5f.

[20] A. Gabriel, S. Fritzsche, C. Creasman, W. Baqai, D. Mordaunt and G. Maxwell, "Incidence of breast and chest wall asymmetries: 4D photography", in Aesthetic Surgery Journal, Vol.31, pp.506-510, 2011, https://dx.doi.org/10.1177/1090820X11410868.

[21] C. Mills, D. Risius and J. Scurr, "Breast motion asymmetry during running", in Journal of Sports Sciences, Vol.33, No.7, pp.746-753, 2015, https://doi.org/10.1080/02640414.2014.962575. 